\title{
Analysis of Defects Formation and Mobility during Ion Irradiation by Coherent Precipitates
}

\author{
Zheng-cao $\mathrm{Li}^{1, *}$, Hiroaki $\mathrm{Abe}^{2}$ and Naoto Sekimura ${ }^{1}$ \\ ${ }^{1}$ Department of Quantum Engineering and Systems Science, School of Engineering, University of Tokyo, Tokyo 113-8656, Japan \\ ${ }^{2}$ Nuclear Professional School, School of Engineering, University of Tokyo, Ibaraki 319-1188, Japan
}

Transmission electron microscopy observation of cross-sectional specimens prepared by focused ion beam milling method have been applied to study the deep radiation damage and depth profile of point defects generated during ion irradiation in $\mathrm{Cu}-1 \mathrm{mass} \% \mathrm{Co}$ alloy specimens by means of coherent precipitates. The specimens were irradiated at a temperature range of 250 to $500^{\circ} \mathrm{C}$ by 4 and $0.6 \mathrm{MeV}$ self $\mathrm{Cu}$ ions to a dose of $0.3 \mathrm{dpa}$. The damage range has been observed at depths well beyond that expected from ion damage range calculations.

(Received October 26, 2005; Accepted December 21, 2005; Published February 15, 2006)

Keywords: ion irradiation, point defect, depth profile

\section{Introduction}

In the last several decades, great efforts have been performed to understand the phenomena of ion beam interactions with materials and change of materials properties induced by ion irradiation from both points of view of its basic understanding and application. However it has not yet been fully understood and still remains as a scientific issue. It is well known that collision cascade initiated from $\mathrm{MeV}$ heavy ion irradiation produces highly concentrated point defects, which can affect the micro-structural evolution and, hence, the properties of materials upon irradiation. ${ }^{1-4)}$

According to simple theoretical considerations, the depth of damage is expected to be comparable to the ion projected range. This relationship is normally found in semiconductors and insulators, while in most metals the observed radiation damage extends significantly deeper into the bulk, especially in those metals with fcc structure. The fact of the deep radiation damage of metals was mentioned by Linker et al. ${ }^{5)}$ and Sood et al. ${ }^{6)}$ As the origin of the deep radiation damage, possible dislocation movement and atom movement mechanisms were proposed by Friedland ${ }^{7)}$ and Fujino ${ }^{8)}$ respectively. However, Friedland and Fujino obtained the damage profiles by the backscattering spectra, in which there was no straight observation of the deep radiation damage and was lack of evidences for the proposed mechanisms. Comparatively, during investigation of the radiation-damage microstructures, transmission electron microscope (TEM) has been a commonly-used and very powerful tool. Properly applied, TEM can give insights into mechanisms of damage evolution which no other technique can deliver.9) However, for observation of those very small defects and defects clusters, TEM has limitations due to its resolution scale.

Thus in the present study, transmission electron microscopy observation of cross-sectional specimens prepared by focused ion beam milling method have been applied to study deep radiation damage and depth profile of point defects generated during ion irradiation in $\mathrm{Cu}-1$ mass $\%$ Co alloy specimens by means of coherent precipitates. The preformed

*Corresponding author, E-mail: zcli@q.t.u-tokyo.ac.jp coherent precipitates in the $\mathrm{Cu}$ rich $\mathrm{Cu}-\mathrm{Co}$ dilute alloy were used as small 'detectors' to probe the point defects formation and mobility during ion irradiation process, in which the interaction between point defects and precipitates can result in the loss of precipitate coherency.

\section{Experimental}

Bulk of $\mathrm{Cu}-\mathrm{Co}$ dilute alloy with a high purity of $99.99 \%$ and a composition of 99\%:1 mass $\%$ was obtained by melting pure Copper and Cobalt in an Arc Melt Furnace with a vacuum of $10^{-4} \mathrm{~Pa}$ at $1800^{\circ} \mathrm{C}$. The nominal impurity content of the stock material is given in Table 1. The obtained bulks were first cold-rolled to a thickness of $0.4 \mathrm{~mm}$, and then punched into disks with a diameter of $3 \mathrm{~mm}$. Afterward, mechanical polishing process was conducted to obtain a pre flat surface. The disks were then solution treated under vacuum at $800^{\circ} \mathrm{C}$ for $5 \mathrm{~h}$, quenched into room temperature and aged at $600^{\circ} \mathrm{C}$ for $20 \mathrm{~h}$ to obtain the well-proportioned Co-rich precipitates. After the above thermal treatment, the disks were electropolished for $40 \mathrm{~s}$ at an applied potential of $1.8 \mathrm{~V}$ in a solution of $80 \% \mathrm{H}_{3} \mathrm{PO}_{4}$ cooled to about $0^{\circ} \mathrm{C}$, so as to obtain the final flat surface before ion irradiation. The low polishing temperature was chosen to prevent gas from being introduced into the specimens during electropolishing process.

Table 1 Impurity analysis of $\mathrm{Cu}-1$ mass\% Co Ingots.

\begin{tabular}{cc}
\hline Element (Impurity) & Determination (mass\%) \\
\hline $\mathrm{Cu}$ & Balanced \\
$\mathrm{Co}$ & 1.05 \\
$\mathrm{Bi}$ & $<0.001$ \\
$\mathrm{~Pb}$ & $<0.001$ \\
$\mathrm{Zn}$ & $<0.001$ \\
$\mathrm{Cd}$ & $<0.0001$ \\
$\mathrm{Ag}$ & $<0.001$ \\
$\mathrm{Fe}$ & $<0.001$ \\
$\mathrm{Te}$ & $<0.001$ \\
$\mathrm{~S}$ & $<0.002$ \\
$\mathrm{P}$ & $<0.0003$ \\
\hline
\end{tabular}


The disks were irradiated with $4 \mathrm{MeV} \mathrm{Cu}{ }^{3+}$ and $0.6 \mathrm{MeV}$ $\mathrm{Cu}^{+}$ions using the High Fluence Irradiation Facility, the University of Tokyo (HIT) at Tokai, Ibaraki, Japan. Self ion irradiation was selected, thus can ignore the effect of impurities introduced during ion irradiation process. The average flux for all samples was about $3.3 \times 10^{15} \mathrm{ions} / \mathrm{m}^{2} \cdot \mathrm{s}$, with fluences ranging from $5.4 \times 10^{16}$ to $1.6 \times 10^{18}$ ions/ $\mathrm{m}^{2}$. This corresponds to a calculated peak damage rate of $6.0 \times 10^{-4} \mathrm{dpa} / \mathrm{s}$ and peak damage levels of 0.01 to $0.3 \mathrm{dpa}$. Table 2 lists the irradiation conditions for this study. The vacuum during irradiation was about $1 \times 10^{-7} \mathrm{~Pa}$. Figure 1 shows the depth-dependent damage profiles for $4 \mathrm{MeV}$ and $0.6 \mathrm{MeV} \mathrm{Cu}$ ions incidents on a copper target as calculated by

Table 2 Irradiation parameters for the ion-irradiated $\mathrm{Cu}-\mathrm{Co}$ foils.

\begin{tabular}{cccc}
\hline Ion & $\begin{array}{c}\text { Temperature } \\
\left({ }^{\circ} \mathrm{C}\right)\end{array}$ & $\begin{array}{c}\text { Dose } \\
(\mathrm{dpa})\end{array}$ & $\begin{array}{c}\text { Dose rate } \\
(\mathrm{dpa} / \mathrm{s})\end{array}$ \\
\hline $4 \mathrm{MeV} \mathrm{Cu}^{3+}$ & $250,300,400,500$ & $0.01,0.03,0.1,0.3$ & $6.0 \times 10^{-4}$ \\
$0.6 \mathrm{MeV} \mathrm{Cu}^{+}$ & 300 & 0.3 & $6.0 \times 10^{-4}$ \\
\hline
\end{tabular}

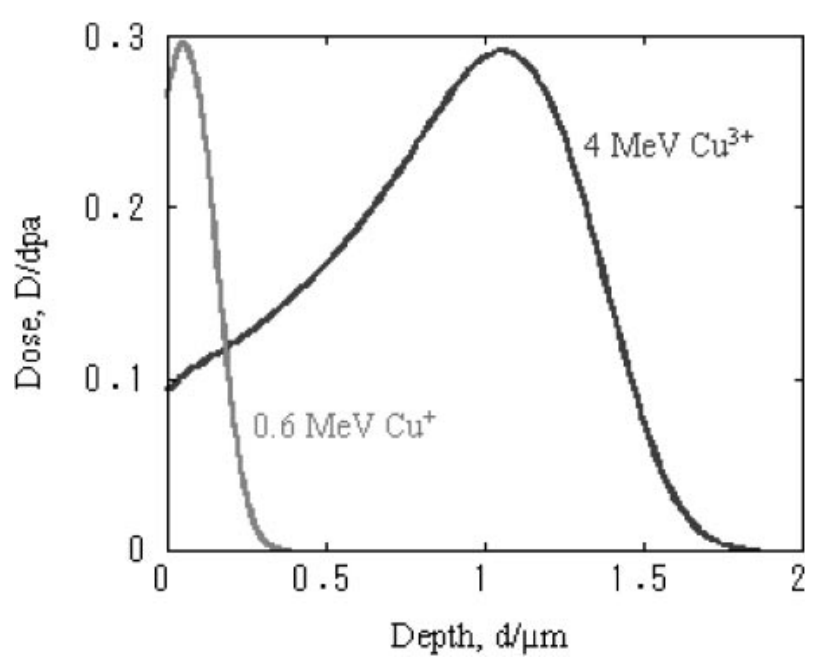

Fig. 1 Calculated 0.6 and $4 \mathrm{MeV} \mathrm{Cu}$ ion displacement damage profile for a copper target as determined from the TRIM 2003 code.
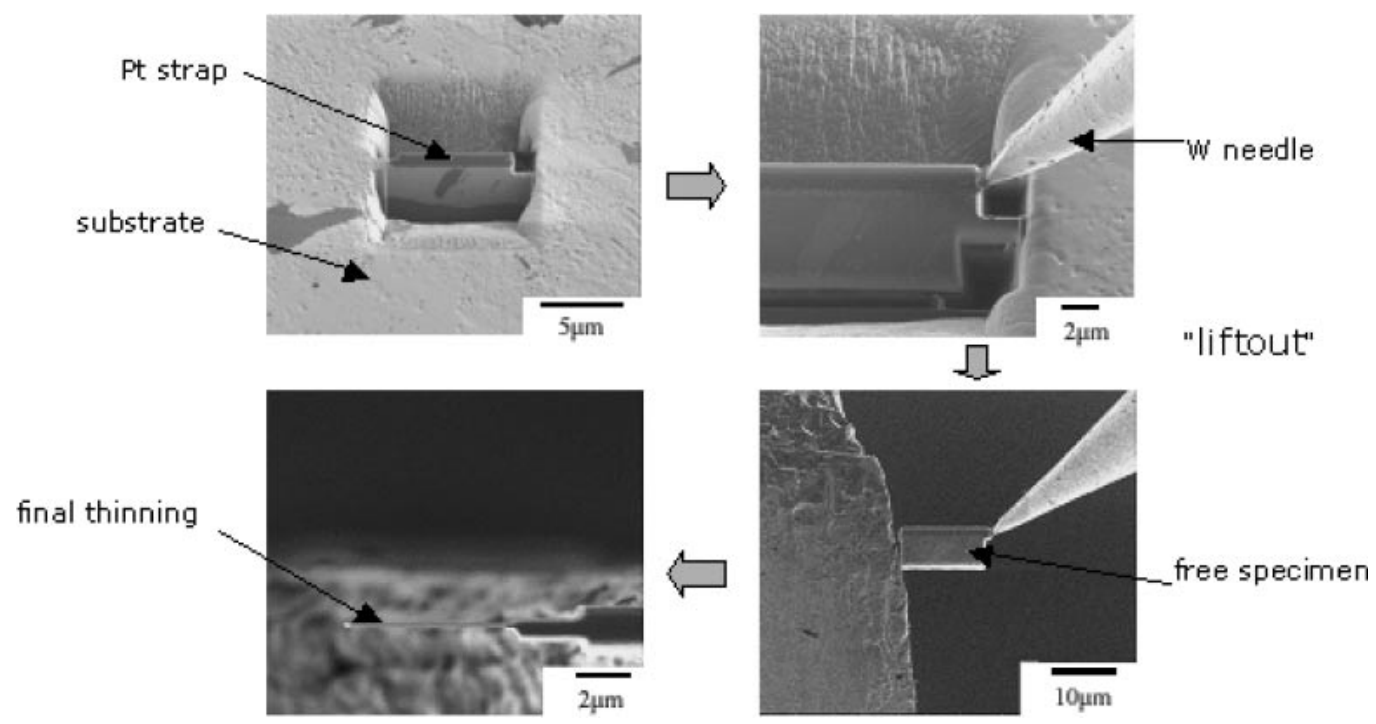

Fig. 2 Preparation process of TEM cross section specimen by means of FIB liftout method.

the TRIM 2003 code. For the case of $4 \mathrm{MeV}$ irradiation, the maximum displacement damage occurs at a depth of about $1100 \mathrm{~nm}$ from the sample surface, and the total depth of the damage zone is about $1800 \mathrm{~nm}$. The degree of displacement damage at the peak-damage depth is about three times greater than that at the specimen surface.

After ion irradiation experiments, in order to reveal a wide spectrum of radiation effect, Focused Ion Beam (FIB) milling method was conducted to thin the samples in cross section, thus the thin section lies parallel to the incident ion beam and contains the entire ion range. FIB systems have already used widely as powerful tools for preparing TEM cross-section specimens. ${ }^{10)}$ Currently, there are two techniques generally used for the FIB preparation of a cross section: the trench technique and the liftout technique. The main advantage of the trench technique over the liftout technique is its higher yield while the main advantage of cross-section specimens prepared using the liftout technique is that their geometry enables them to be tilted through large angles in a TEM. In the present study, we have chosen the liftout technique using a FIB system of FEI Quanta 200 3D and the preparation process can be seen in Fig. 2. In order to decrease the damage introduced by FIB system, a method using a low $\mathrm{keV}(5 \mathrm{keV})$ FIB to thin a cross-section specimen has been conducted in the present study. Finally the specimens were examined in a JEOL 200CX electron microscope.

\section{Results and Discussion}

Since the coherent precipitates will be used as small detectors, we need to form coherent precipitates which nucleate homogeneously throughout the matrix. A conventional precipitation treatment was conducted before irradiation experiments. The heat treatment typically consists of homogenizing the alloy at high temperatures, followed by a fast quenching process to room temperature to retain the supersaturation effectively from high temperature. And it is subsequently aged isothermally at a reasonably high temperature for a predetermined time to form the precipitates. In the present study, the typical dilute alloy, $\mathrm{Cu}-1$ mass\%Co alloy 
(a) Before irradiation

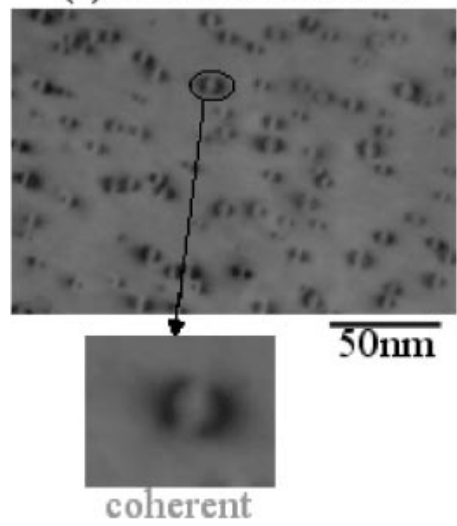

(b) $1.0-1.2 \mu \mathrm{m}$

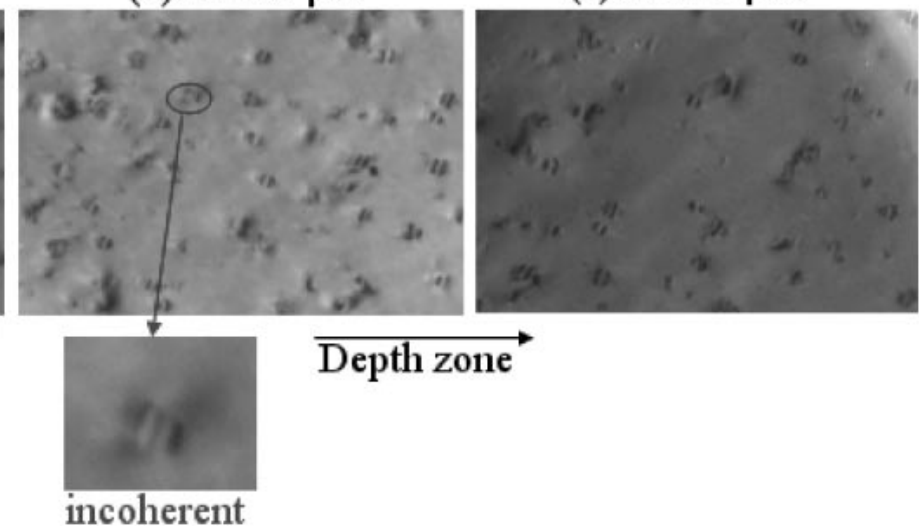

Fig. 3 TEM images of Co-rich precipitates (a) before irradiation; (b, c) after irradiation at $400^{\circ} \mathrm{C}$ to a peak dose of $0.3 \mathrm{dpa}$. Incident depth ranging (b) from 1.0 to $1.2 \mu \mathrm{m}$ and (c) from 1.9 to $2.1 \mu \mathrm{m}$.

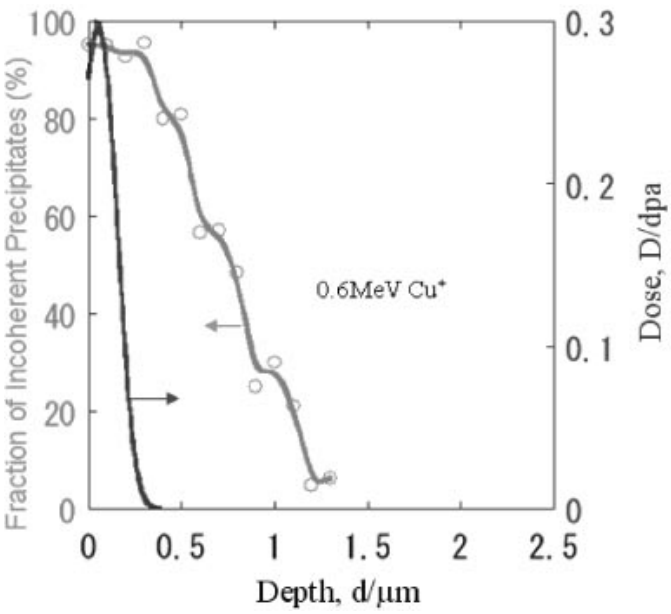

(a)

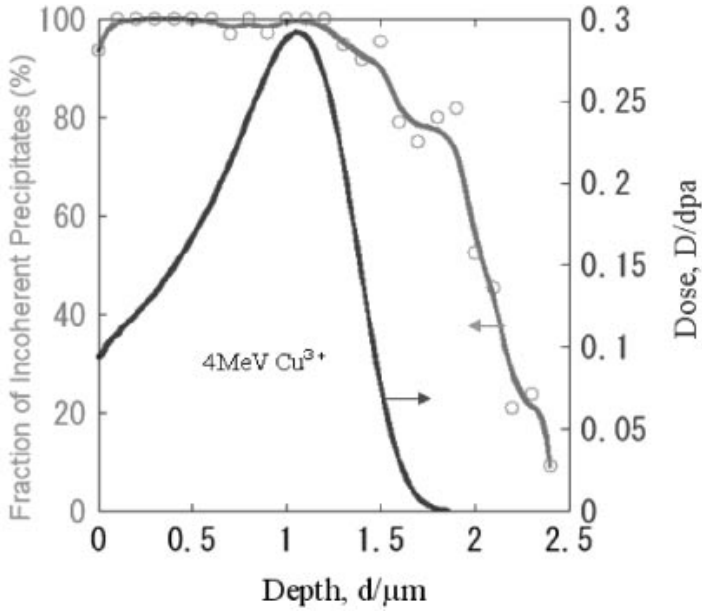

(b)

Fig. 4 Dependence of depth on the fraction of incoherent precipitates: (a) $0.6 \mathrm{MeV}$, (b) $4 \mathrm{MeV}$.

was first solute treated at $800^{\circ} \mathrm{C}$ for $5 \mathrm{~h}$, and then quenched to room temperature, followed by an aging process at $600^{\circ} \mathrm{C}$ for $20 \mathrm{~h}$ to form the precipitates. The formed precipitates were typical of those observed in previous aging experiments on $\mathrm{Cu}-\mathrm{Co}$ dilute alloys, i.e. spherical, coherent precipitates which nucleate homogeneously throughout the matrix, as shown in Fig. 3(a). According to the equilibrium phase diagram of the $\mathrm{Cu}-\mathrm{Co}$ system, the composition of the precipitate is around $90 \% \mathrm{Co}$ and $10 \% \mathrm{Cu}$. In the transmission electron microscopy, the strain contrast of the spherical coherent precipitate produces an elliptical image, split by a line of no contrast that is perpendicular to the reciprocal lattice vector of the particle. The mean diameter of the precipitates formed in the experiment was about $10.9 \mathrm{~nm}$, and the particle number density was about $9.1 \times 10^{15} \mathrm{~cm}^{-3}$, yielding a precipitate volume fraction of about $0.62 \%$.

It is known that in the idealized case of a coherent precipitate, the interface between the precipitates and the matrix is typified as an internal surface where constrained recombination of defect and anti-defect occurs. The interface of the coherent precipitate with the matrix is modeled as containing a distribution of saturable traps.
One can imagine that a certain volume of the parent phase (matrix) is removed and replaced by a different volume of product phase (precipitate). The difference in volume leads to a dilatational strain which is positive or negative, depending on the sign of the volume change. In the present case of $\mathrm{Cu}-$ Co dilute alloy (lattice constants: $a_{\mathrm{Cu}}=0.3615 \mathrm{~nm}, a_{\mathrm{Co}}=$ $0.3545 \mathrm{~nm}$ ), the lattice parameter of the precipitate is smaller than that of the matrix and the coherency strain can be relieved by absorbing free-migrating interstitials induced by ion irradiation.

Transmission electron micrographs of $\mathrm{Cu}-1$ mass $\% \mathrm{Co}$ specimens irradiated at $400^{\circ} \mathrm{C}$ to a peak dose of $0.3 \mathrm{dpa}$ are shown in Figs. 3(b) and (c). Comparatively, Fig. 3(a) shows the micrograph of an unirradiated specimen. Comparing these TEM micrographs, one can easily find that the preformed spherical coherent precipitates have lost their coherency during heavy ion irradiation, and transformed from coherent precipitates into incoherent ones. It is known that freely-migrating interstitials, generated by ion irradiation, can be absorbed at sinks, such as surfaces, interfaces or grain boundaries, et al. However we have employed bulk material whose grain size is much larger than the regions 
investigated in the present study. Therefore majority of the interstitials can be trapped at the precipitates because of their affinity in terms of lattice strain. Agglomeration of such interstitials results in the loss of coherency. The authors must note that the loss of coherency occurs readily because it was observed even in the case of extremely low dose such as $0.01 \mathrm{dpa}$ in the present study. To be brief, the principal effect of ion irradiation on the aged $\mathrm{Cu}-1$ mass $\% \mathrm{Co}$ alloy was loss of precipitate coherency. Heavy ion irradiation in the present study did not measurably change the size or number density of the spherical Co-rich precipitates. We should note here that no dislocation loops have been observed in the present study.

Also, the depth dependences on the fraction of incoherent precipitates upon $0.6 \mathrm{MeV} \mathrm{Cu}^{+}$and $4 \mathrm{MeV} \mathrm{Cu}^{3+}$ irradiation have been shown in Figs. 4(a) and (b) respectively. One can see that the coherent precipitates situated up to well about $1 \mu \mathrm{m}$ beyond the end-of-range have also lost their coherency, which resulted from the migration of free interstitials well beyond the damage zone, due to the low migration energy of $\mathrm{Cu}$ interstitials (about $0.2 \mathrm{eV}$ ). It is interesting that the deep radiation effects happened independent on the energies of the incident ions. Actually, in the present study, all the observed irradiated $\mathrm{Cu}-\mathrm{Co}$ specimens have lost precipitate coherency as a result of ion irradiation. Even in the low dose of $0.01 \mathrm{dpa}$, the precipitates within the damage zone have also lost their coherency. That is to say, the principle effect of ion irradiation on the coherent precipitates in $\mathrm{Cu}-\mathrm{Co}$ alloy is loss of coherency, and the coherency loss is efficient to detect the formation and mobility of the interstitials upon ion irradiation.

\section{Conclusions}

Deep radiation damage has been observed by means of coherent precipitates through transmission electron microscopy observation of cross-sectional specimens prepared by focused ion beam milling method. The damage range has been observed at depths well beyond that expected from ion damage range calculations.

\section{REFERENCES}

1) M. Kiritani, T. Yoshiie, S. Kojima, Y. Satoh and K. Hamada: J. Nucl. Mater. 174 (1990) 327.

2) S. Ishino, T. Muroga and N. Sekimura: Nucl. Eng. Des./Fusion 2 (1985) 3.

3) Z. C. Li, D. P. Yu and B. X. Liu: Phys. Rev. B 65 (2002) 245403.

4) B. X. Liu, Z. C. Li and H. R. Gong: Surf. Coat. Technol. 196 (2005) 2.

5) G. Linker, M. Gettings and O. Meyer: Ion Implantation in Semiconductors and other Materials, ed. B. L. Crowder (Plenum, New York, 1973) p. 465.

6) D. K. Sood and G. Dearnaley: J. Vat. Sci. Technol. 12 (1975) 463.

7) E. Friedland, N. G. van der Berg, O. Meyer and S. Kalbitzer: Nucl. Instrum. Methods Phys. Res. B 118 (1996) 29.

8) Y. Fujino, Y. Igarashi and S. Nagata: Phys. Rev. B 63 (2001) 100101.

9) M. L. Jenkins: J. Nucl. Mater. 216 (1994) 124.

10) R. M. Langford and A. K. Petford-Long: J. Vac. Sci. Technol. A 19 (2001) 2186. 